\title{
Analisa Temperature Flame dan Efisiensi Termal Dengan Pengaruh Rasio Udara Bahan Bakar Solar Pada Burning Zone Terhadap Tekanan dan Temperatur
}

\section{Tasya Dwiputri Arza*1, Kevin Rahmad Fajar Dwi Saputra², Tahdid ${ }^{3}$, Muhammad Taufik ${ }^{4}$, Sutini Pujiastuti Lestari ${ }^{5}$}

1,2,3,4,5,6Program Studi Teknik Energi, Jurusan Teknik Kimia,

Politeknik Negeri Sriwijaya, Indonesia

Email: 'tasyadwiputri97@gmail.com, ${ }^{2}$ kevinrahmad08@gmail.com

\begin{abstract}
Abstrak
Boiler merupakan suatu bejana tertutup yang berfungsi untuk merubah air menjadi air panas atau uap yang bertekanan dan memiliki temperatur yang tinggi. Double drum cross section water tube boiler merupakan boiler yang menggunakan dua drum (steam drum dan water drum) yang terhubung dengan water tube dan superheater sebagai tempat terjadinya proses proses pemanasan air dan uap air. Dimana posisi tube disusun secara melintang dengan tujuan memperluas area tube sehingga luas area perpindahan panas pada boiler menjadi lebih besar kemudian menggunakan kemiringan pada tube sebesar $65^{\circ}$ dengan tujuan agar mempercepat penguapan pada molekul air. Bahan bakar yang digunakan pada penelitian kali ini menggunakan bahan bakar cair yaitu solar. Dari hasil penelitian menghasikan kinerja alat Water Tube Boiler yang baik yaitu pada rasio udara bahan bakar 9,75 (excess 18\%), dimana efisiensi Thermal yang didapatkan sebesar 67,3\%, dengan temperature steam sebesar $206,9^{\circ} \mathrm{C}$, tekanan steam sudah mencapai tekanan optimum yaitu sebesar 5 bar. Kendala yang terjadi yaitu pada komponen yang tidak bisa menahan tekanan dan temperatur yang tinggi sehingga menyebabkan produksi steam yang dihasilkan menjadi tidak optimal. Sehingga penelitian kali ini dilakukan pengupgradean pada sistem Injection Boiler Feed Water dengan penambahan sistem Drain yang diharapkan mampu menahan turbulensi pada level gauge saat terjadinya proses kontinyu. dan sistem Secondary agar produksi steam yang didapatkan berlangsung secara steady state atau Non steady state sehingga didapatkan hasil pembakaran dan produksi steam yang optimal.
\end{abstract}

Kata kunci: Boiler Pipa Air, Efisiensi Termal, Rasio Udara Bahan Bakar, Tekanan, Temperatur.

\section{Analysis of Flame Temperature and Thermal Efficiency with The Effect of Solar Fuel Air Ratio on Burning Zone to Pressure and Temperature}

\begin{abstract}
Boiler is a closed vessel that functions to convert water into hot water or steam which is pressurized and has a high temperature. Double drum cross section water tube boiler is a boiler that uses two drums (steam drum and water drum) connected to a water tube and a superheater as a place for the process of heating water and steam. Where the position of the tube is arranged transversely with the aim of expanding the tube area so that the heat transfer area in the boiler becomes larger then using a slope on the tube of $65^{\circ}$ with the aim of accelerating evaporation of water molecules. The fuel used in this study uses liquid fuel, namely diesel. From the results of the study, the performance of the Water Tube Boiler tool was good, namely the air-fuel ratio of 9.75 (excess $18 \%$ ), where the Thermal efficiency obtained was $67,3 \%$, with a steam temperature of $206.9^{\circ} \mathrm{C}$, the steam pressure had reached The optimum pressure is 5 bar. Constraints that occur are components that cannot withstand high pressures and temperatures, causing the resulting steam production to be not optimal. So that this research is done upgrading the injection boiler feed water system with the addition of a drain system which is expected to be able to withstand turbulance at the gauge level during a continuous process. And secondary system so that the obtained steam production takes place in a steady state or non steady state so that optimal combution results and steam production are obtained.
\end{abstract}

Keywords: Air Fuel Ratio, Pressure, Temperature, Thermal Efficienc, Water Tube Boiler.

\section{PENDAHULUAN}

Mesin - mesin konversi energi merupakan sumber tenaga yang akan mengoperasikan berbagai mesin 
produksi dalam suatu industri, salah satunya adalah boiler. Boiler merupakan suatu bejana tertutup yang berfungsi untuk merubah air menjadi air panas atau uap yang bertekanan dan memiliki temperatur yang tinggi (Juriwon, 2019) [1]. Air panas atau steam pada tekanan dan suhu tertentu mempunyai nilai energi yang kemudian digunakan untuk mengalirkan panas dalam bentuk energi kalor ke suatu proses. Jika air didihkan sampai menjadi steam, maka volumenya akan meningkat sekitar 1600 kali, menghasilkan tenaga yang menyerupai bubuk mesiu yang mudah meledak, sehingga sistem boiler merupakan peralatan yang harus dikelola dan dijaga dengan sangat baik (Siregar, 2017) [4]. Uap yang dihasilkan dari boiler ini pada umumnya berasal dari proses pembakaran yang menggunakan bahan bakar gas, cair maupun bahan bakar padat (Sugiharto,2020) [7]. Dimana tekanan dan temperature fluida yang dihasilkan tersebut dapat dimanfaatkan untuk berbagai macam keperluan, seperti untuk turbin uap, pemanas ruangan, mesin uap, dan lain sebagainya (Hasibuan 2013) [6]. Ruang bakar dalam boiler memegang peranan yang sangat penting dalam melakukan pembakaran untuk menghasilkan energi panas yang digunakan untuk merebus air dalam pipa. Sistem pemipaan yang sering digunakan yakni secara Longitudinal tube dan cross section tube. Longitudinal tube artinya susunan tube sejajar dengan steam drum, sedangkan cross section tube artinya tube tersusun secara melintang terhadap steam drum [3].

Water Tube Boiler merupakan sebuah boiler yang dimana air umpan berada didalam pipa mengalir masuk ke dalam drum air yang tersirkulasi dipanaskan oleh gas pembakar membentuk steam pada daerah uap dalam drum, boiler ini dipilih jika kebutuhan steam dan tekanan steam sangat tinggi seperti pada kasus boiler untuk pembangkit tenaga. Water Tube Boiler yang sangat modern dirancang dengan kapasitas steam antara $4.500-$ $12.00 \mathrm{~kg} / \mathrm{jam}$ dengan tekanan sangat tinggi (UNEP, 2006) [5].

Pada penelitian kali ini adanya pengupgradean pada sistem injection boiler feed water, control level air pada steam drum akan dipasang sistem drain (pembuangan), dimana penambahan tersebut bertujuan agar pada saat pembacaan level ketinggian air yang ada didalam drum dapat terbaca dengan jelas dan tepat. serta pada sistem secondary udara pembakaran akan dipasang blower dengan laju pemasokan yang terkontrol. (Oktaviani, 2021) [2] Dimana pada saat penelitian sebelumnya, drum air terhubung langsung pada water level gauge sehingga pada saat pembacaan ketinggian level air akan mengalami kesulitan, karena adanya gelombang air sehingga akan menyebabkan air tidak tenang pada saat pembacaan level ketinggian.

Pada keadaan ini air telah mencapai titik didihnya atau suhu jenuhnya, yang dijenuhkan oleh energi panas. Jika tekanannya tetap penambahan lebih banyak panas tidak mengakibatkan kenaikan suhu lebih lanjut, namun menyebabkan air akan membentuk steam jenuh (Sriwijaya, 2020) [5].

Bahan bakar solar merupakan bahan bakar minyak nabati hasil destilasi dari minyak bumi mentah. Bahan bakar ini berwarna kuning coklat yang jernih. Berikut beberapa spesifikasi bahan bakar solar :

\begin{tabular}{|c|c|c|c|c|c|}
\hline \multirow[t]{2}{*}{ No. } & \multirow[t]{2}{*}{ Karakteristik } & \multirow[t]{2}{*}{ Satuan } & \multicolumn{2}{|c|}{ Batasan } & \multirow[t]{2}{*}{ Metode Uji } \\
\hline & & & Min. & Maks. & \\
\hline 1. & $\begin{array}{c}\text { Berat Jenis (pada suhu } \\
15^{\circ} \mathrm{C} \text { ) }\end{array}$ & $\mathrm{kg} / \mathrm{m}^{3}$ & 815 & 870 & D4052/D1298 \\
\hline 2. & $\begin{array}{c}\text { Viskositas (pada suhu } \\
40^{\circ} \mathrm{C} \text { ) }\end{array}$ & $\mathrm{mm}^{3} / \mathrm{s}$ & 2,0 & 4,5 & D445 \\
\hline 3. & Kandungan Sulfur & $\% \mathrm{~m} / \mathrm{m}$ & - & $\begin{array}{c}0,35 \\
0,30 \\
0,25 \\
0,05 \\
0,005\end{array}$ & D4294/D5453 \\
\hline 4. & Penguapan & ${ }^{\circ} \mathrm{C}$ & - & 370 & D86 \\
\hline 5. & Titik Nyala & ${ }^{\circ} \mathrm{C}$ & 52 & - & D93 \\
\hline
\end{tabular}

sumber : Kepdirjen Migas No.28 Tahun 2016 [9]

\section{METODE PENELITIAN}

Rancang bangun upgrade Water Tube Boiler terdiri dari delapan unit utama yaitu steam drum, water drum, water tube, burner, ruang bakar, superheater, pompa, kompresor, dan blower. Sistem tersebut dilengkapi dengan instrumen pendukung yaitu pressure indicator, temperature indicator, valve, pressure safety valve, water level gauge dan drain valve.

Proses pembuatan rancang bangun beserta penelitian akan dilakukan di Laboratorium Program Studi Teknik Energi Jurusan Teknik Kimia Politeknik Negeri Sriwijaya Palembang. Berikut ini merupakan uraian waktu dan tempat pelaksanaan penelitian: 
1. Pengupgradean Water Tube Boiler

Waktu : Maret - April 2021

Tempat : Laboratorium Teknik Energi Jurusan Teknik Kimia Politeknik Negeri Sriwijaya.

2. Pengujian Water Tube Boiler

Waktu : April-mei 2021

Tempat : Laboratorium Teknik Energi Jurusan Teknik Kimia Politeknik Negeri Sriwijaya.

3. Analisa Hasil Percobaan

Waktu : Juni 2021

Tempat : Laboratorium Teknik Energi Jurusan Teknik Kimia Politeknik Negeri Sriwijaya

Penelitian yang dilakukan dengan menggunakan prototype Boiler sistem Non steady state / steady state dengan menggunakan double drum yang masing- masing memiliki fungsi yakni sebagai feed water drum dan steam drum untuk pengolahan air umpan boiler menjadi steam yang berkualitas saturated maupun superheated memiliki beberapa variabel yang diambil antara lain variabel tetap dan variabel berubah.

1. Variabel tetap, yaitu :
a. Air umpan
$: 50 \mathrm{~L}$
b. Solar
$: 6,4 \mathrm{~L}$

2. Variabel berubah, yaitu :
a. Udara excess : $6 \%, 10 \%, 14 \%, 18 \%$, dan $22 \%$
b. Rasio udara bahan bakar (saturated steam) : 9,44, 9,80,10,16, 10,51, 10,87
c. Rasio udara bahan bakar (superheated steam) : 15,78; 16,38; 16,97; 17,57; 18,16

\section{HASIL DAN PEMBAHASAN}

Pada penelitian ini, digunakan 5 variabel rasio udara bahan bakar yakni 9,44, 9,80, 10,16, 10,51, 10,87 pada proses pembuatan saturated steam dan sedangkan proses superheated steam menggunakan rasio sebesar 15,$78 ; 16,38 ; 16,97 ; 17,57 ; 18,16$.

\subsection{Pengaruh Rasio Udara Bahan Bakar Solar Terhadap Temperature Flame pada Superheated Steam}

\section{Grafik Hubungan Rasio Udara /BB Solar terhadap Temperature Flame $\left({ }^{\circ} \mathrm{C}\right)$}

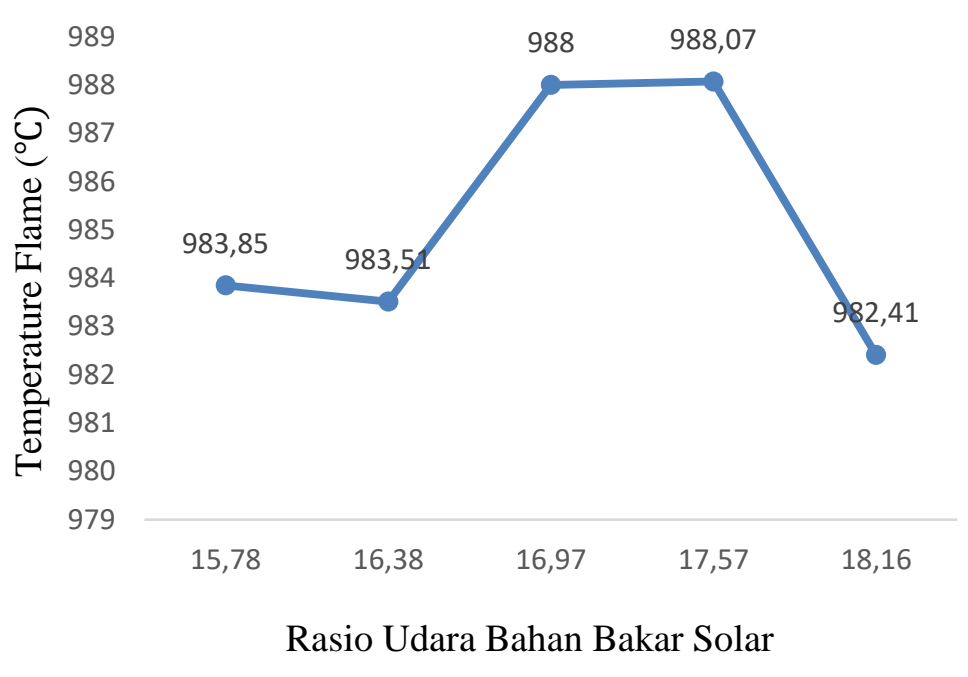

Gambar 1. Grafik Hubungan Rasio Udara/Bahan Bakar Solar Terhadap Temperatur Flame

Dari gambar grafik diatas dapat kita lihat hubungan antara rasio udara bahan bakar solar dan level ketinggian air terhadap temperature flame ada turun dan naiknya. Dimana pada grafik menunjukkan pada rasio udara/BB 15,78 temperatur flame yang didapat sebesar $983,85^{\circ} \mathrm{C}$, pada rasio udara/BB 16,38 temperatur flame yang didapat sebesar $983,51^{\circ} \mathrm{C}$, pada rasio udara/BB 16,97 temperatur flame yang didapat sebesar $988^{\circ} \mathrm{C}$, pada rasio udara/BB 17,57 temperatur flame yang didapat sebesar $988,07^{\circ} \mathrm{C}$, dan pada rasio udara/BB 16,38 temperatur flame yang didapat sebesar $982,41^{\circ} \mathrm{C}$. 
Pada rasio udara/BB ke-3 temperature flame terjadi kenaikan yang signifikan, hal ini terjadi dikarenakan pembakaran didalam furnace menghasilkan energi kalor yang tinggi, dan pada rasio udara/BB ke-4 temperatur mengalami keadaan yang optimal dimana temperature flame pada rasio ke-4 memiliki nilai yang hampir sama atau hanya mengalami kenaikan temperatur yang sangat kecil. Namun, pada rasio udara/BB ke-5 terjadi penurunan temperature flame, sehingga rasio udara/BB ke-5 kurang efisien untuk digunakan pada pembakaran solar di water tube boiler tersebut, karena bila jumlah udara berlebih melebihi batas yang dianjurkan maka, dapat merugikan karena dapat menurunkan nilai temperature flame dan menyerap panas termanfaatkan dalam gas buang.

\subsection{Pengaruh Rasio Udara Bahan Bakar Solar Terhadap Effisiensi Thermal Pada Superheated Steam}

\section{Grafik Hubungan Rasio Udara /BB Solar terhadap Efisiensi Thermal (\%)}

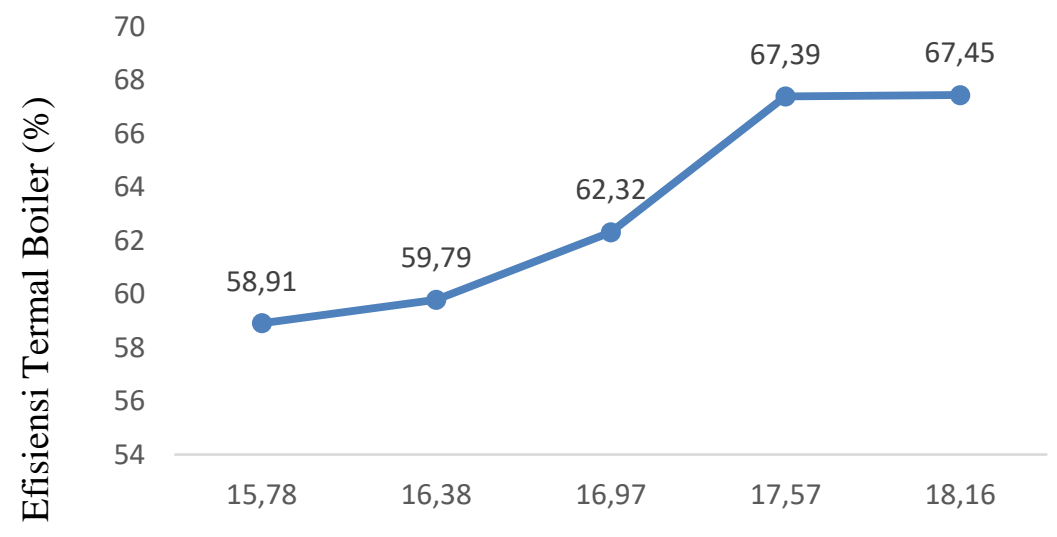

Rasio Udara Bahan Bakar Solar

Gambar 2. Grafik Hubungan Rasio Udara/Bahan Bakar Solar Terhadap Efisiensi Thermal

Dari gambar grafik diatas dapat kita lihat hubungan antara rasio udara bahan bakar solar dan level ketinggian air terhadap efisiensi thermal terjadi peningkatan. Dimana pada grafik menunjukkan semakin tinggi nilai rasio udara maka efisiensi thermal yang akan didapat akan semakin tinggi. Dan juga apabila semakin tinggi level ketinggian air maka efisiensi thermal yang akan dihasilkan akan meningkat pula. Dimana kenaikan efisiensi thermal tersebut terjadi karena terjadi kenaikan jumlah panas yang diterima fluida steam sehingga meningkatkan jumlah kalor yang terserap sehingga efisiensi thermal akan meningkat.

Pada rasio udara/BB ke-1 efisiensi thermal maksimum yang dicapai pada rasio ini hanya sebesar 58,91\%. Pada rasio udara/BB ke-2 efisiensi thermal maksimum yang dicapai hanya sekitar 59,79\%. Dan pada rasio udara/BB ke-3 efisiensi thermal yang dicapai hanya sebesar $62,32 \%$. Sedangkan pada rasio udara/BB ke-4 dan ke-5, kedua rasio ini mampu mencapai efisiensi thermal yang cukup tinggi yakni 67,39\% dan 67,45\%.

Sehingga dari gambar grafik diatas rasio udara/BB yang lebih optimal itu pada rasio udara/BB yang ke-4 yakni sebesar 17,57.

\subsection{Pengaruh Rasio Udara Bahan Bakar Solar Terhadap Temperature Saturated Steam}

Dari kondisi level ketinggian air $50 \%$ dapat dilahat pada Gambar 4.1 pada rasio udara bahan bakar 9. 44 (6\%) yang mengalami naik turunya kondisi temperatur yang dapat mempengaruhi produksi steam yang dihasilkan, sedangkan rasio udara yang ingin dicapai yaitu memiliki Temperatur yang optimal pada saat proses pembakaran sehingga dapatkan dibuktikan bahwa rasio udara bahan bakar yang optimal yaitu pada rasio udara 10.87 (22\%) dengan Temperatur yang optimal mencapi $167^{\circ} \mathrm{C}$.

Grafik pengaruh rasio udara BB solar terhadap temperarur saturated steam dimaksudkan itu mengetahui rasio udara bahan bakar yang optimal untuk menghasilkan temperatur steam yang lebih optimal. Semakin tinggi temperatur steam yang dihasilkan maka semakin bagus kualitas rasio udara bahan bakar. Suatu pembakaran akan menghasilkan panas yang berkualitas apabila rasio udara dan bahan bakar yang tepat. 


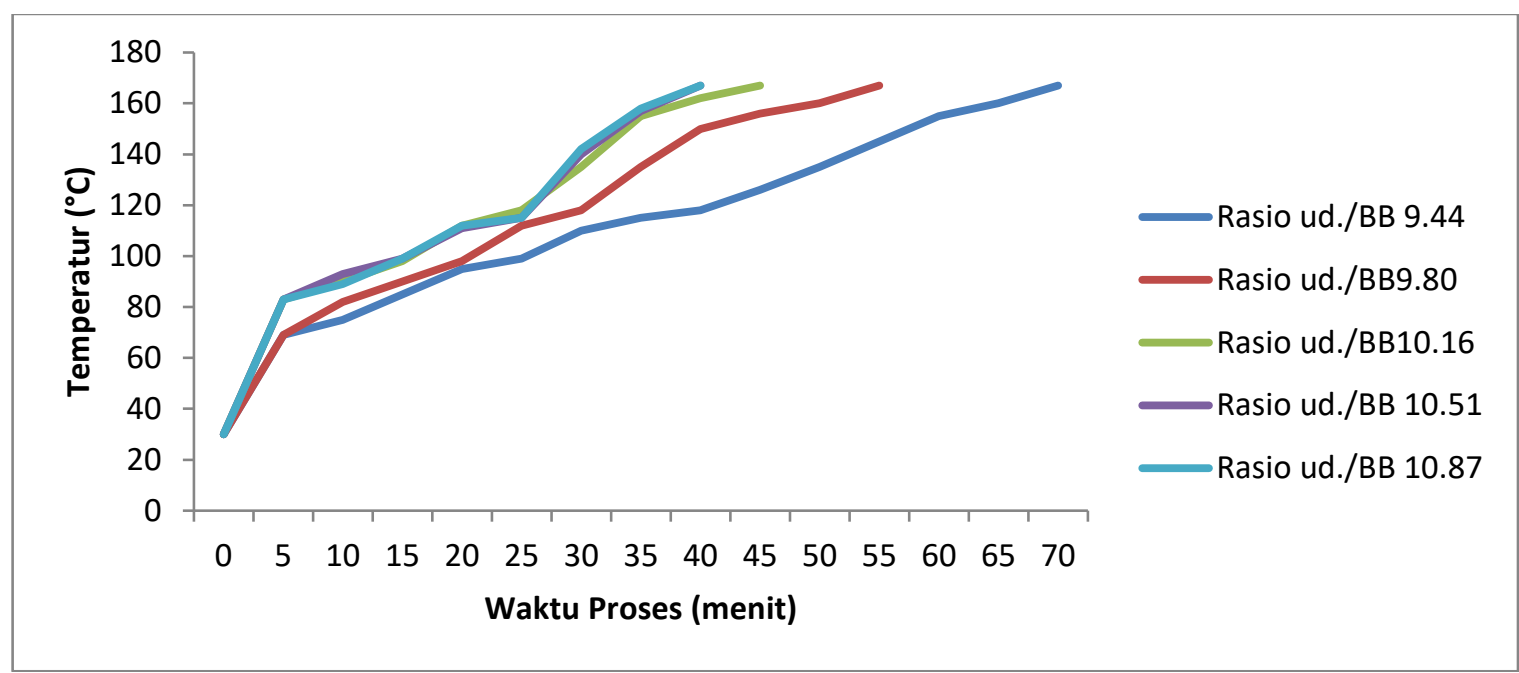

Gambar 3. Grafik Pengaruh Rasio Udara BB Solar Terhadap Temperatur Saturated Steam

\subsection{Pengaruh Rasio Udara Bahan Bakar Solar Terhadap Tekanan Saturated Steam}

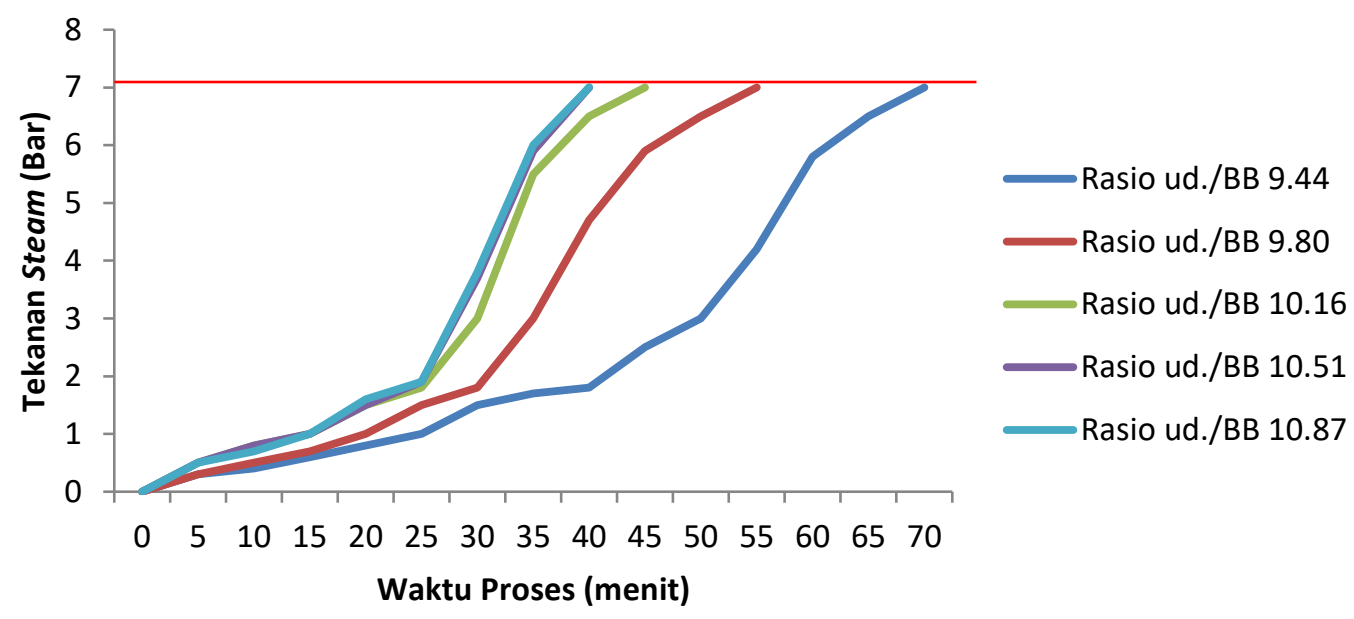

Gambar 4. Grafik Pengaruh Rasio Udara BB Solar Terhadap Tekanan Saturated Steam

Dari gambar grafik diatas diperoleh bahwa untuk mencapai tekanan 7 bar, rasio udara bahan bakar solar $9.44(6 \%)$ memiliki waktu proses selama 70 menit, pada rasio udara $9.80(10 \%)$ memiliki waktu proses selama 55 menit, rasio udara 10.16 (14\%) memiliki waktu proses selama 45 menit, rasio 10.51 (18\%) memiliki waktu proses selama 40 menit, dan pada rasio 10.87 (22\%) memiliki waktu proses selama 40 menit. Berdasarkan nilai yang diperoleh tersebut dapat dinyatakan bahwa rasio udara bahan bakar yang paling optimal terhadap tekanan dari ke 5 rasio diperoleh yaitu pada rasio udara 10.87 (22\%). Grafik pengaruh rasio udara bahan bakar solar terhadap tekanan saturated steam dimaksud untuk mengetahui rasio udara bahan bakar yang optimal dan signifikan untuk menghasilkan tekanan steam desain.

\section{KESIMPULAN}

Setelah membuat rancang bangun upgrade water tube boiler dan melakukan penelitian tentang menganalisa flame temperature dan menghitung efisiensi termal dengan pengaruh rasio udara bahan bakar solar pada burning zone terhadap tekanan dan temperatur pada two drum water tube boilr, dapat disimpulkan bahwa, semakin tinggi rasio udara/bahan bakar maka semakin tinggi pula nilai temperature flame dan efisiensi thermal yang akan dihasilkan. Pada kondisi superheated steam nilai rasio udara/bahan bakar yang optimal adalah sebesar 17,57 dimana menghasilkan temperature flame sebesar 988,07 oC. Pada saturated steam kondisi operasi yang optimal terdapat pada rasio udara bahan bakar solar ke 5 yaitu 10.87 (22\%) yang menghasilkan tekanan 7 bar dalam waktu 40 menit, temperatur $167 \mathrm{oC}$ dan entalpi $2768 \mathrm{~kJ} / \mathrm{kg}$ dalam waktu 40 menit. pada kondisi operasi tersebut, Steam yang dihasilkan menjadi optimal. Nilai efisiensi thermal yang didapat adalah sebesar 67,39\%. 


\section{DAFTAR PUSTAKA}

[1] Juriwon, Analisis Energi Boiler Pipa Air Menggunakan Bahan Bakar Solar. Jurnal Hasil Penelitian Dan Ulasan Ilmiah, vol. 8, no.2, pp. 7-13, 2017

[2] Y. Oktaviani, "Efisiensi Termal Produksi Steam Ditinjau Dari Rasio Udara Bahan Bakar Solar Pada Cross Section Water Tube Boiler", vol. 12, no. 1, pp. 18-22, 2021

[3] A. Saputra, F. P. Putra, Tahdid, A. Manggala, and Zurohaina. "Pengaruh Level Ketinggian Air Terhadap Effisiensi Thermal Pada Cross Section Water Tube Boiler Menggunakan Gas Dan Solar Produksi Saturated Steam Proses Kontinyu Effect of Water Level To Thermal Efficiency in Cross Section Water Tube Boiler Using Gas", vol. 11, no. 02, pp. 50-54, 2020

[4] M. A. A. Siregar, "Analisa Pembakaran Pada Ruang Bakar Boiler Untuk Kebutuhan 30 Ton / Jam Tekanan 20 Bar Dengan Bahan Bakar Cangkang Dan Fiber", pp. 49, 2017

[5] P. N. Sriwijaya, "Pengaruh Rasio Udara Bahan Bakar Solar Dan Gas Terhadap Kualitas Saturated Steam Pada Sistem Two Drum Water Tube Boiler Effect Of Air Fuel Ratio Of Diesel And Gas Fuel On Saturated Steam Quality In The Two". vol. 11, no. 2, pp. 38-43, 2020

[6] UNEP, “Bahan Bakar dan Pembakaran”, http://www.eneryefficienciasia.org

[7] H. C. Hasibuan, and F. H. Napitupulu, F. H. "Analisa Pemakaian Bahan Bakar Dengan Melakukan Pengujian Nilai Kalor Terhadap Perfomansi Ketel Uap Tipe Pipa Air Dengan Kapasitas Uap 60 Ton/Jam". E-DInamis, vol. 4. no. 4, 2013

[8] A. Sugiharto, "Perhitungan Efisiensi Boiler Dengan Metode Secara Langsung pada Boiler Pipa Api", Majalah Ilmiah Swara Patra, vol. 10, no. 2, pp. 51-57, 2020. https://doi.org/10.37525/sp/2020-2/260

[9] Kepdirjen Migas No.28 Tahun 2016. 